Article

\title{
Fish liver discards as a source of long chain omega-3 polyun- saturated fatty acids
}

Charlotte Jacobsen ${ }^{1 *}$, Simone Andrea Warncke ${ }^{1}$, Sussie Hjorth Hansen ${ }^{1}$, Ann-Dorit Moltke Sørensen ${ }^{1}$

\author{
${ }^{1}$ National Food Institute, Technical University of Denmark, Building 201, Kemitorvet, DK-2800 Kgs. Lyngby, \\ Denmark; food@food.dtu.dk \\ * Correspondence: chja@food.dtu.dk
}

\begin{abstract}
The intake of omega-3 polyunsaturated fatty acids (PUFA) of the average consumer is generally low and products like fish oils high in omega-3 PUFA have become a popular dietary supplement. There is a need for more sources of omega-3 PUFA to cover the increasing demand. This study investigated whether livers from different lean fish species could be a potential new source of oils rich in omega-3 PUFA. The seasonal variation in lipid content, fatty acid composition, peroxide value and free fatty acid content of livers from cod, hake, ling, coalfish and monkfish was determined and the effect of storage conditions on the fishing vessel (ice vs frozen) was studied. Generally, the lipid content and composition of the livers from the five fish species varied similarly during the two years of sampling period with significantly lower values in spring (March, April) and higher values in fall (November, October). Storage conditions were found to have no significant effect on the quality and oil composition. Monkfish livers were less suitable for production of omega3 oil due to their lower lipid and EPA content and higher FFA levels. Coalfish had higher fluctuations in oil composition during sampling period, which potentially makes a standardised quality difficult to obtain. Cod, hake and ling were the most suitable species for fish liver oil production.
\end{abstract}

Keywords: Hake, ling, cod, monkfish, coalfish (saithe), omega-3 PUFA

\section{Introduction}

It is commonly known that most products of marine origin are essential in a healthy diet because they are rich in long chain omega- 3 polyunsaturated fatty acids (PUFA). The important omega-3 PUFA in the diet are eicosapentaenoic acid (EPA; C20:5n-3) and docosahexaenoic acid (DHA; 22:6n-3). Consumption of omega-3 PUFA contributes to maintenance of health and significantly reduces the risk of cardiac related diseases and stroke [1, 2]. Omega-3 PUFA are also important for the neurological functions as EPA and DHA are components of brain and nervous tissue and therefore important for neurological development in infants and also for maintaining mental health $[2,3]$.

Omega-3 oil supplements, especially in encapsulated form, are gaining increasing popularity, as a way for the average consumer to reach an intake that lives up to the daily requirements of EPA and DHA as recommended by different organizations such as EFSA. Most of the omega-3 oils used for dietary supplements are imported from the two 
largest exporters, Peru and Chile, which account for respectively $31 \%$ and $15 \%$ of the total world production of fish oil [4]. These fish oils are mainly produced from sardines and anchovies, which are also used to produce fish oil for fish feed. The production of farmed fish and thereby the need for long chain omega-3 PUFA for both fish feed and for human consumption is increasing. However, it is not possible to increase the catch of anchovies, sardines and other fish species used for fish oil production due to sustainability issues. Therefore, other sources of long chain omega-3 PUFA are urgently needed.

Up to 44 million tons worldwide of unutilized fish raw material is discharged annually, meaning that there is a huge potential in taking advantage of this waste and for example use it in the production of marine oils [5]. Previous studies on the potential of utilising fish waste have mainly focused on fatty fish with known high PUFA levels, such as salmon, trout, anchovies [6-8].

White fish species are lean and low in fat in the flesh, but deposit a high content of oil and fat in the liver. Cod liver is already used for extraction of omega-3 PUFA in some parts of the world [4]. Ling, coalfish (saithe), hake and monkfish are other examples of white fish species, which are caught for human consumption in Scandinavia. On board the fishing vessel, viscera including livers are removed from the fish and discarded back into the sea because of the low economic value of these parts of the fish. Moreover, viscera and liver are rich in enzymes, which potentially can degrade the fish muscle and thereby reduce its quality. According to Statistic Denmark, approximately 33,000 and 22,000 tons of cod species were caught in Denmark in 2018 and 2020, respectively [9]. 40 $\%$ of the fish are utilized for consumption after trimming. This number could be increased by $10 \%$ by utilizing the liver, and even more by including all viscera.

Due to the unsaturated nature of omega-3 PUFA, they are highly susceptible to lipid oxidation. This could be a problem if livers are to be brought back to the shore for further processing. Likewise, lipases present in livers may degrade triglycerides and phospholipids and produce high levels of free fatty acids.

The aim of this study was to evaluate the potential of livers from five different species of white fish (ling, coalfish, hake, cod and monkfish) caught in Danish waters of the North Sea for being used as a new source of omega-3 oil. This includes investigation of the seasonal variation in the lipid content and fatty acid composition of the livers. Furthermore, the aim was to evaluate whether the storage temperature on board the fishing vessel (ice storage versus frozen storage) will affect the oxidative status measured by the peroxide value (PV) and lipid hydrolysis as measured by the content of free fatty acids.

\section{Materials and Methods}

\subsection{Raw material}

For this study fish livers from five fish species (ling (Molva molva), monkfish (Lophius piscatorius, coalfish also called saithe (Pollachius virens), hake (Merluccius merluccius) and cod (Gadus morhua)) were obtained from two vessels; HG 306 Tobis (Hirtshals, Denmark) and HM 635 Karbak (Thisted, Denmark) throughout a period from August 2016 to July 2018 (samples from Tobis only received in August 2016). The fish were caught in the North Sea, mostly along the southern part of the Norwegian coast. The livers were 
removed from the fish before being stored on the vessel either on ice or frozen at $-20{ }^{\circ} \mathrm{C}$ for up to six days. When received at the harbor of Hirtshals, they were picked up by a truck and transported at $-20^{\circ} \mathrm{C}$ to DTU. Upon arrival, the livers were transferred to a freezing room at $-40^{\circ} \mathrm{C}$ where they were kept until analyses were performed. For each species, up to five livers were sampled per fishing trip. In most cases, two to four livers were collected and results are reported as means \pm standard deviation. For each liver sample all analyses were performed in duplicate.

\subsection{Methods}

\subsubsection{Dry matter}

Dry matter of the fish liver was determined after chopping according to the AOAC Official methods of analysis [10].

\subsubsection{Oil content}

Oil content in the fish liver was determined in chopped solid samples according to Bligh and Dyer [11] using a reduced amount of solvent but keeping the ratio between water, methanol and chloroform. Results are presented as $\%$ of the total sample.

\subsubsection{Fatty acid methyl ester (FAME)}

The FAME profile of the fish liver was determined by analysing samples of B\&D extract corresponding to 20-50 mg lipid. Fatty acid profile was determined based on the American Oil Chemist's Society (AOCS) official method Ce 1b-89 [12] and Ce 1i-07 [13] with some modifications. Approximately $2 \mathrm{~g}$ of Bligh and Dyer extract was weighted in methylation glass tubes and evaporated under a stream of nitrogen until dryness. A mixture containing $100 \mu \mathrm{L}$ of internal standard solution (C23:0), $200 \mu \mathrm{L}$ of heptane with BHT and $100 \mu \mathrm{L}$ of toluene was added to the dry extract. Samples were methylated in a microwave oven (Microwave 3000 SOLV, Anton Paar, Ashland, VA, USA) for 5 min. at $100{ }^{\circ} \mathrm{C}$ and power of $500 \mathrm{~W}$. After methylation, heptane with BHT $(0.7 \mathrm{~mL})$ and saturated salt water $(1 \mathrm{~mL})$ were added. The upper phase (heptane) was transferred into HPLC vials and analysed using gas chromatography (HP-5890 A, Agilent Technologies, Santa Clara, CA, USA). Fatty acid methyl esters were separated by the GC column Agilent DB wax 127$7012(10 \mu \mathrm{m} \times 100 \mu \mathrm{m} \times 0.1 \mu \mathrm{m})$ (Agilent technologies, Santa Clara, CA, USA). Standard mix of fatty acids methyl esters (Sigma, St. Louis, MO, USA) was used for fatty acid identification. Fatty acids were quantified as area \% of total fatty acids.

\subsubsection{Free fatty acids (FFA)}

The FFA content was determined according to AOCS Official Methods Ca 5a-40 [14] by titration with $0.1 \mathrm{M} \mathrm{NaOH}$ on samples consisting of 10-15 $\mathrm{g}$ B\&D extract mixed with 20 $\mathrm{ml}$ chloroform, $25 \mathrm{ml}$ ethanol and 5 drops of phenolphthalein indicator.

\subsubsection{Peroxide value}


Peroxide value was determined on the Bligh and Dyer extract using the method of Shantha and Decker [15]. Results are presented as meq. peroxides ( $\mathrm{ROOH}) / \mathrm{kg}$ oil.

\subsubsection{Data analysis}

To get an overview of the differences between months and species for all analysed parameters (dry matter, oil content, FAME profile, free fatty acid content and peroxide value), a principal component analysis (PCA) was conducted using The Unscrambler® X software (Camo Software AS, Oslo, Norway). All variables were weighted by 1/standard deviation. A PCA was also performed on data from each species. For this PCA, all data were used without discriminating between whether livers had been frozen or not. The samples from Tobis (August 2016) were, however, not included in the PCA because they had much higher levels of peroxides and free fatty acids than samples from Karbak).

\section{Results and discussion}

\subsection{Results and discussion}

\subsubsection{Principal component analysis of all data}

The raw data from the analyses include samples from the following nine months; July, August and November in 2016, January, March, September, October in 2017, March and April in 2018. Most months have samples of all fish species, excluding October 2017 and March 2018 where no ling or hake were caught, respectively. The raw data consist of 280 samples, grouped together according to species and sampling months. Samples from July 2016 were not included because the storage condition of these samples was unknown. To provide a graphical overview of the relationship and patterns in the variation in the data, a principal component analysis (PCA) on all data was performed.

The PCA plot for the data set including all mean values of the livers from the five fish species caught per month. In the scores plot in Figure 1(a), clusters of the different species of fish are observed with most monkfish samples located to the left and most coalfish samples located to the right. Overlaps between the different species are observed, indicating similarities between the five species. By comparison of Figure 1(a) with the loadings plot in Figure 1(b), it is found that monkfish generally had high FFA content, but lower dry matter and oil content than the other species. The opposite was observed for coalfish. Some coalfish samples were located in the same direction as PV, suggesting that PV was high in these coalfish samples. Based on Figure 1, cod, coalfish, ling and hake were found to generally have higher content of EPA and DHA than monkfish. The different sampling months were located within the inner ellipse of the loadings plot, indicating that different sampling months contributed less to explaining the variation in the data than other variables (measured variables such as PV, FFA, oil, EPA and DHA) which were located between the inner and outer ellipses.

\subsubsection{Effect of storage conditions}

A PCA was also performed to analyse whether storage conditions (on ice (I) or frozen (F)) had any effect on fatty acid composition, FFA or PV for all the fish species. 
However, no correlation between the measured variables and storage conditions was observed (Figure A1).

To further study whether storage conditions affected individual species, PCA models were constructed for each fish species. It was observed that ling, hake and coalfish had indications of slight effects on storage conditions (data not shown). For ling specifically, it was observed that the PV was generally higher for samples that had been stored in frozen conditions only (Figure A2). However, the opposite was observed for cod for which fish stored on ice at sea generally had a higher PV (Figure A3). Furthermore, it was observed from the PCA model that the days of storage at sea did not affect the oil composition nor the peroxide value and percentage of free fatty acids in the fish liver. Due to these observations, the effect of storage condition and time at sea was neglected when plotting and examining the data of the individual species and their corresponding PCA plots as shown in Figure 2.

Figure 2 shows a clear correlation between dry matter and lipid content in all fish species. Such a correlation is expected as oil content contributes to the total dry matter content. This interpretation is further confirmed by the raw data in Figure $3 a$ and $3 b$, which show that the patterns in the seasonal variation in dry matter and lipid content are very similar. Comparison of the values of dry matter and lipid content also shows that the lipids constituted between 72 to $95 \%$ of the dry matter content. This was in accordance with a study by Eliassen and Vahl [16] who investigated seasonal variations in water and fat content of cod livers. In the PCA plot in Figure 2, there is a repeating pattern of April '18 being negatively correlated to dry matter and oil content. This finding suggests that the values of these variables in this specific month were lower compared to samples from other months. The observations regarding low dry matter and lipid content in April '18 were confirmed by the raw data in Figure 3(a), which show that both dry matter and lipid content were lowest in April '18 for all species except hake. Furthermore, dry matter content for monkfish was lower compared to the other fish species, but relatively stable throughout the year with a content of 45-55 \%. Ling, coalfish, hake and cod all followed a similar pattern with a slight increase in dry matter content observed in autumn (around October) and a decrease in spring (around March) followed by the previously mentioned low dry matter content in April '18 of approximately $60 \%$. Coalfish had the highest dry matter content in October (both 2017 and 2018) with values of 80-82 \%, and lowest content of 60-70\% in March 2017 and 2018. The general pattern for lipid content throughout the seasons was observed to follow the pattern for dry matter content, as mentioned above. The lipid content for monkfish was observed to be the lowest, ranging from a content between 30-45 \% while the other four fish species generally had a lipid content ranging from between $50-80 \%$.

Røjbæk et al. [17] reported that lipid content of Baltic cod varied between 50 to $60 \%$, which was in accordance with the levels observed in the present study (55-63\%). Falch et al. [18] compared lipid contents in livers from cod caught in spring, autumn and summer in the Barents Sea (59 to 76 \%), Icelandic waters (45 to $65 \%$ ) and South coast of Ireland (30 to $40 \%$ ). The livers of the present study thus resembled livers from the Icelandic waters 
the most. Icelandic waters are closer to the fishing grounds along the southern part of the Norwegian coast where the fish in this study were caught than the other fishing grounds in the study by Falch et al. [18]. They also reported the lipid content in coalfish (saithe) and ling caught from the same fishing grounds as mentioned above, except that no ling were caught in the Barents Sea. Again, the values obtained for livers from the Icelandic waters (46 to $72 \%$ for coalfish and 47 to $74 \%$ for ling) were more similar to the values obtained in this study (48 to $75 \%$ for coalfish and 51 to $66 \%$ for ling) than the values obtained from other fishing grounds. Falch et al. [18] performed a two-way analysis of variance on the effect of fishing ground and season. They found that the effect of fishing ground was significant for all fish species whereas season significantly influenced lipid content in ling and coalfish, but not in cod. Dominguez-Petit et al. [19] reported lipid content to vary between 62 to $75 \%$ in European hake, which also corresponded well with the observations in our study.

The obvious difference in both dry matter and oil content between monkfish and coalfish, ling, hake and cod may be due to monkfish being from the Lophiiformes order while the other four are from the Gadiformes order of fish. Likewise, according to United States Department of Agriculture, the overall fat content in raw monkfish is found to be $1.52 \%$ while it is $0.67 \%$ for cod [20]. This difference and the possibility of monkfish storing its fat differently from cod species (e.g. less fat in the liver) may be the cause for differences observed in the data.

\subsubsection{Fatty acid composition}

Because the scope of this study is to evaluate the potential of the livers as a source of oils rich in long chain omega-3 fatty acids, only the sum of all omega-3 PUFA and omega6 PUFA as well as EPA and DHA are shown and discussed here.

\subsubsection{Sum of omega-6 PUFA}

As observed in Figure 4(a), all fish types had a similar omega-6 PUFA content ranging from 2-3 \% until March 2017. The values then differed between species, with hake and monkfish experiencing a decrease in September 2017 to approximately $1.5 \%$. The omega-6 PUFA \% continued to remain low for monkfish until April 2018, whereas the content increased significantly for hake to ca. $3 \%$ in October 2017. Thereafter, the omega6 content for hake followed the same patterns as those of ling, coalfish and cod ranging from $2.5-4 \%$ throughout the rest of the sampling period. High standard deviations were observed for some of the data points due to large variation between individual samples of fish. Røjbek et al. [17] reported that the total content of omega-6 PUFA in cod livers varied during the season from $4.8-5.3 \%$ in triacylglycerols and 3.2-4.5\% in phospholipids. Méndez [21] reported a seasonal variation of omega-6 PUFA (18:2) in hake from 2.0 to $2.8 \%$. McGill and Moffat [22] studied the fatty acid composition in different commercial liver oils. They found that monkfish and saithe liver oils contained $1.7 \%$ and $1.6 \%$ omega-6 PUFA $(18: 2)$. These values were all within the ranges observed for the different species in the current study. 


\subsubsection{Sum of omega-3 PUFA in \% of total fatty acids}

All species were observed to follow a similar pattern through the seasons (Figure $4 \mathrm{~b}$ ). The omega-3 PUFA content in the livers was observed to range from approximately 18 to $29 \%$, decreasing slightly in both March 2017 and March 2018 compared to the previous months. Overall cod liver was found to have the highest values of omega-3 PUFA in the sampling period. From September 2017 to March 2018 all fish species were observed to experience a decrease in omega-3 PUFA level, with the coalfish's content fluctuating the most to a value of $19 \%$. Ling livers also had a low content of omega-3 PUFA towards the end of the sampling period (only $20 \%$ ). Røjbek et al. [17] found that omega-3 PUFA levels in cod livers from Baltic varied during the season from $35-42 \%$ in triacylglycerols and from 46 to $51 \%$ in phospholipids. These values were substantially higher than those found in our study. The fatty acid composition in livers varies with the diet of the fish, which may be different between cods caught in the Baltic Sea and in the North Sea. This could explain the large difference in the omega-3 PUFA content between the two studies.

\subsubsection{Content of EPA in \% of total fatty acids}

The livers from all five species of fish were found to once again follow a similar pattern as shown in Figure 4(c). Cod liver was observed to have a relatively stable EPA $\%$, which ranged between 6 to $9 \%$ and it generally contained the highest amount of EPA compared to the other species. Falch et al. [18] found that EPA content in cod livers from the Icelandic waters varied between $10.1 \%$ in the spring to $8.5 \%$ in the autumn. In our study, EPA content in cod livers was highest in the early autumn and lowest in the early spring. Monkfish liver was found to have the lowest EPA content, which agreed with the interpretation from the PCA in Figure 1. The EPA content in monkfish livers varied between 4.5 to $6.5 \%$. McGill and Moffat [22] observed an EPA content of $7.7 \%$ in commercial monkfish liver oil, which is a little higher than observed in our study. The EPA content in livers from ling and hake varied between the levels observed for livers from monkfish and cod. Falch et al. [18] found that the EPA content in ling livers from Icelandic waters was lowest in the autumn (4.8\%) and highest in the spring (6.3\%). Again, this was in contrast to the pattern observed in our study, where ling livers had the highest values in the early autumn. We found slightly higher levels of EPA in our study. EPA content in hake livers from Argentina-Uruguay varied from 5.0 to $8.4 \%$ with the highest values observed in late summer and the lowest in winter [21]. In our study, there was no clear seasonal effect in the EPA content of hake livers despite the fact that EPA content varied between the different months.

Coalfish livers had a large variation in their EPA content (4.2 to $9 \%$ ). Although, a similar large variation was not observed for coalfish livers caught in the Icelandic waters (6.3 to $9.0 \%$ ), the EPA levels were almost in the same range.

\subsubsection{Content of DHA in livers as \% of total fatty acids}


The values of DHA in the livers from the five species generally ranged between 10$15 \%$ DHA (Figure 4d). The variation in DHA content during the seasons was not as significant as changes in EPA content. The highest values were observed for cod livers whereas the lowest were observed for livers from monkfish and ling. High standard deviations for monkfish and ling were observed in March 2017 meaning that the lower DHA \% may be caused by a random and unexplainable variation within samples of the two species in that month. The observations in Figure 1 that ling and monkfish livers had lower in EPA and DHA content corresponded with Figure 4(c,d) of raw data of all species and all months. Likewise, Figure 1 also showed that livers from coalfish, hake and cod were generally richer in EPA and DHA which was generally also found in raw data in Figure 4(c,d). For both cases, some months were not in agreement with these observations, and a longer sampling period may be necessary to draw any final conclusions. The study by Falch et al. [18] reported lower DHA values for livers from cod (6.0 to $9.7 \%$ ), ling (5.4 to $9.4 \%$ ) and coalfish (6.2 to $9.4 \%$ ) when these species were caught in the Icelandic waters compared to the findings in this study. In contrast, livers from hake caught in waters of Argentina-Uruguay had slightly higher levels of DHA (12.7-17.6 \%) than found in our study [21]. In contrast, McGill and Moffat [22] found DHA levels of 12.4 and $14.2 \%$ in commercial coalfish and monkfish livers oils. These values are within the ranges found in the present study. Differences between fatty acid compositions reported in the different studies may be due to the different diets of the fish. Moreover, seasonal variations are also due to the reproductive cycle - at least in female species [17]. Figure $3 \mathrm{~b}-\mathrm{d}$ indicate deviating values in spring (around April and March). It is known that these five fish species generally have spawning season around spring (ranging between January and May) [23]. Spawning season has in previous studies been shown to cause reduced muscle tissue in favor of gonad maturation in farmed Atlantic cod [24,25]. The growth of fish is normalized post spawning season (around October). In gadoid species like cod, the liver is the primary energy reserve as the liver lipids are mobilized when more energy is required [26]. It is a possibility that the extra used energy before and during spawning season results in lower lipid content in the liver, meaning less oil in the liver will be present for extraction. However, the livers in this study are both from females and males and the effect of the spawning season might be lower than if the livers had only been from females. Nevertheless, the data in Figure 3(a) show lower lipid content in the samples for April and March, which may support the mentioned hypothesis. To fully investigate a correlation between seasons (including spawning period) and liver oil attributes, more data are required. This means that more data during the summer seasons and generally more data of the same seasons in different years would be beneficial.

\subsubsection{Liver oils as a new source of fish oils}

Moving the focus back to the possibilities of utilizing the fishing waste from the five species of fish in the production of marine oil for human consumption, the recommended values of EPA and DHA in fish liver oil are 7-16 \% and 6-18 \% respectively [27]. The most suitable species for the production of liver oil are therefore cod and hake as 
they generally kept a high content of both EPA and DHA. Coalfish livers were also observed to have high contents of EPA and DHA. However, the livers from this species seemed to vary more during the seasons and the EPA content dropped to $5 \%$ and below in some months. This may make coalfish less suitable for an all-year production than cod and hake. Ling livers only had higher EPA levels than recommended for two of the sampling months, but DHA levels were above the recommended levels in all sampling months. Monkfish livers had lower EPA levels than recommended in all sampling months, but DHA levels were within the recommended levels. Because monkfish livers had the lowest lipid content throughout the sampling period this was the least suitable fish for liver oil production.

In a high-quality fish oil ready for human consumption, the omega-6 PUFA content should be as low as possible to combat the average consumer's generally higher intake of omega-6 PUFA compared to omega-3 PUFA. In a typical cod liver oil, the total omega-6 fatty acid content is $3.6 \%$ while the omega- 3 content is approximately $24 \%$ [28]. A similar ratio between omega- 6 and omega-3 PUFA was observed for all fish species throughout the sampling period. This showed that the oils in the fish livers have great potential for production of a fish oil with a quality similar to cod liver oil based on the ratio between omega-6 and omega-3 PUFA.

\subsubsection{Quality of the liver}

\subsubsection{Peroxide value $(P V)$}

Figure 3(c) shows that from July 2016 to January 2017 the PVs in the liver from the various fish were similar ( $<1 \mathrm{meq} / \mathrm{kg}$ ). However, an increase in PV was observed for coalfish, ling and cod starting in March 2017. Coalfish liver was found to have the highest value in October 2017 of $2.8 \mathrm{meq} / \mathrm{kg}$ while livers from hake and monkfish still maintained a PV under $1 \mathrm{meq} / \mathrm{kg}$ throughout these months. It is important to note that the standard deviations for the coalfish and cod samples were observed to be high for the months September 2017, October 2017 and March 2018, indicating that the data points were spread out over a wider range of values and were generally not very consistent. When examining the raw data, the storage condition was observed not to correlate well with the observed deviations, which may indicate that variation between individual samples was the reason for the variation in data.

\subsubsection{Free Fatty Acid (FFA)}

The FFA content generally differed for the various fish species with livers from hake and ling sharing the same pattern throughout the seasons (Figure 3d). Monkfish livers had the highest values of FFA, peaking in March 2017 and September 2017 with values of approximately $6 \%$ FFA.

The overall quality of fish oil is dependent on the quality of raw materials (fish liver) and the processing that takes place. In marine products, avoidance of oxidation and rancidity is the primary focus point. Both PV and FFA \% of the liver may increase during 
processing, and these values should therefore be as low as possible in the raw materials. Preferably, the final fish oil product should have low values of PV and FFA \%, indicating low oxidation and higher stability of the product. Crude fish oil intended for human consumption generally has a peroxide value ranging between 3-20 meq/ $\mathrm{kg}$ [29], the lower the value the better the quality of the final refined fish oil. For the FFA content, the recommended value for crude marine oils is $1-7 \%$, however it is more commonly found to be between $2-5 \%$ [29].

As observed in Figure 3(d), the obtained FFA \% for all fish types were found to be < $3 \%$, which indicates that they are suitable for human consumption. Even if the fish liver may experience further oxidation and hydrolysis that will lower the quality during the oil extraction process, the extracted crude oil will undergo further refining and deodorization steps that will remove free fatty acids, lipid hydroperoxides and volatile decomposition productions from the oils. It is the volatile oxidation products that are responsible for undesirable fishy and rancid off-flavors. Nevertheless, monkfish with a FFA content close to $7 \%$ may be less suitable for oil production than the other fish species. None of the fish livers were found to have a too high peroxide values, which make them suitable for producing fish oil for human consumption.

\subsection{Figures, Tables and Schemes}

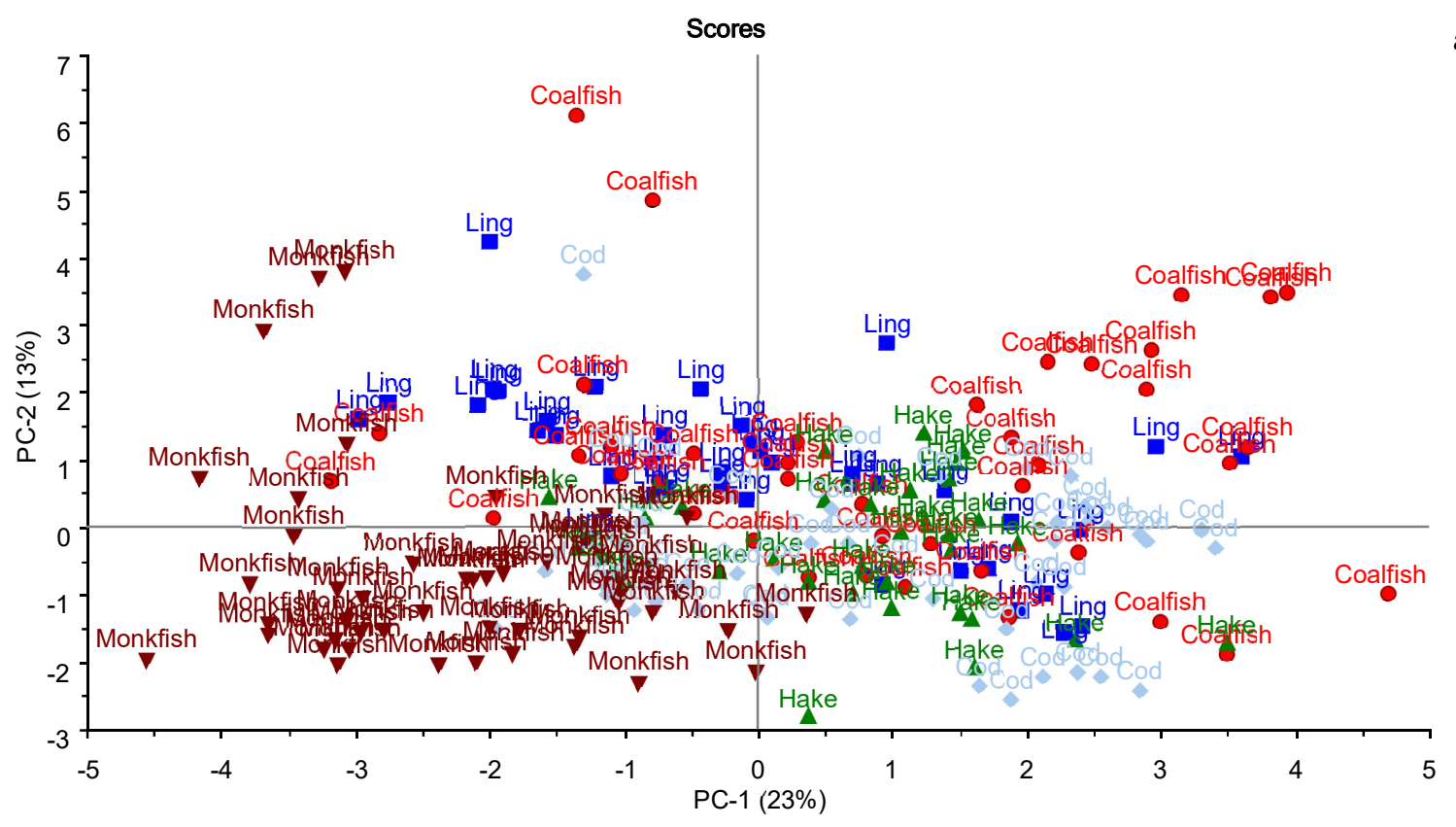

a)

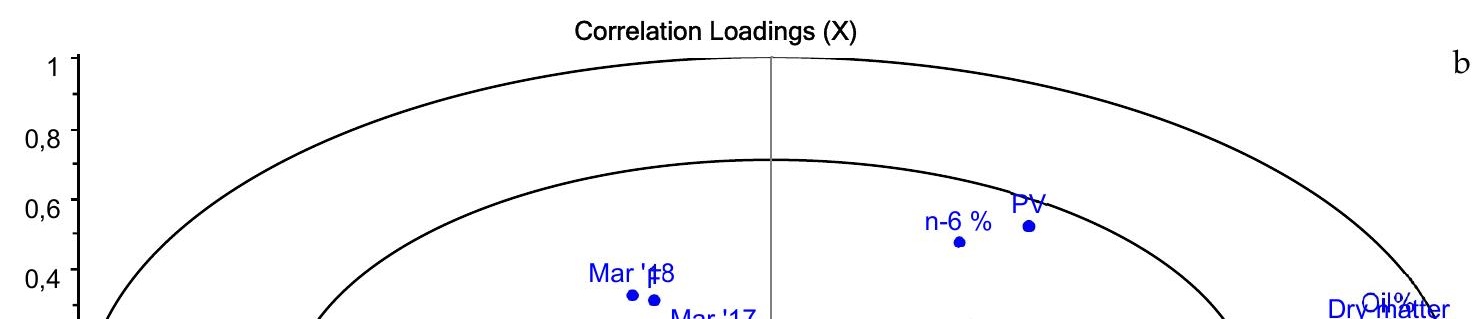

b) 
Figure 1. This is a figure. Schemes follow the same formatting.

Table 1. This is a table. Tables should be placed in the main text near to the first time they

Figure 1. PCA plot for all fish species per month and the collected data for dry matter content, oil content, fatty acid composition, peroxide value, free fatty acid content. Data for July 2016 are not included in the PCA plots. (a) scores plot of all the different samples and (b) loadings plot of variables including selected fatty acids, month of sampling and quality parameters. Variables located within the inner ellipse explains less than $50 \%$ of the variation in the data. Variables located between the two ellipses explain between 50 and $100 \%$ of the variation in the data. 

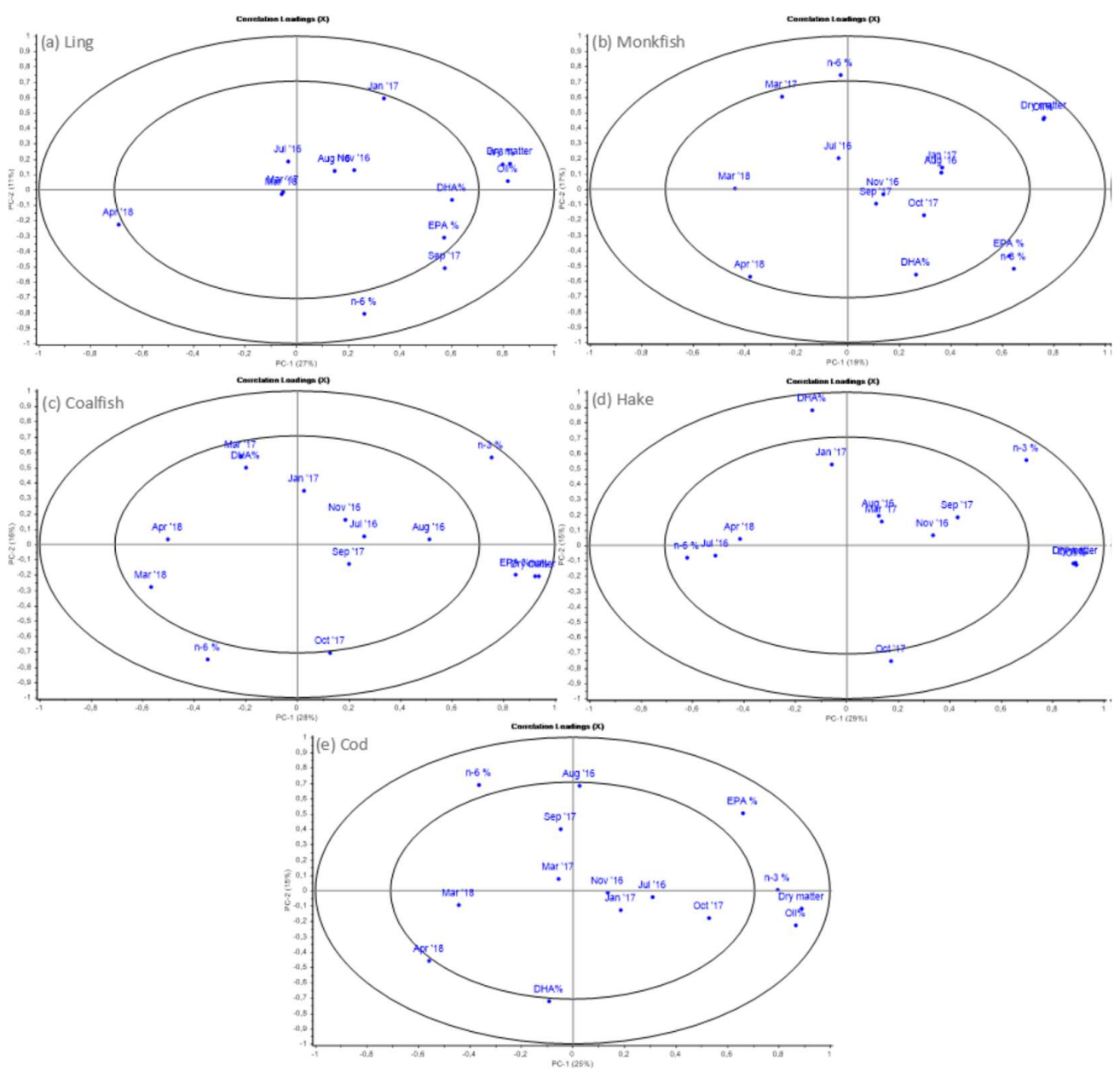

Figure 2. Individual PCA plots for all fish species including specific sampling months and the data collected for dry matter content, oil content and fatty acid composition (n-6, n-3, EPA, DHA). Peroxide value and free fatty acids. Storage conditions are not included. Variables located within the inner ellipse explain less than $50 \%$ of the variation in the data. Variables located between the two ellipses explain between 50 and $100 \%$ of the variation in the data. 


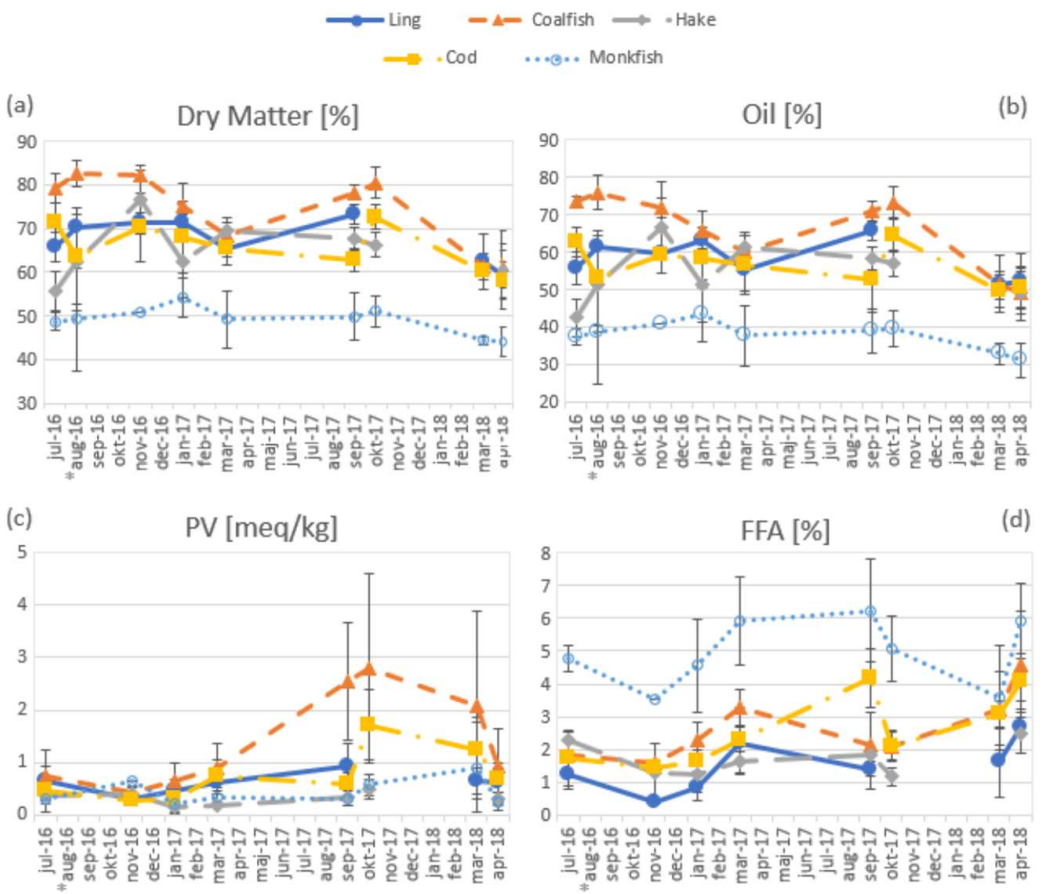

Figure 3. Overview of raw data from analyses of fish samples. (a) Dry matter, (b) Oil, (c) peroxide value and (d) FFA \%, as a function of time for sampling, including all fish species. All samples excluding August ' 16 are from Karbak while data for August '16 are based fish caught by Tobis marked with a star.
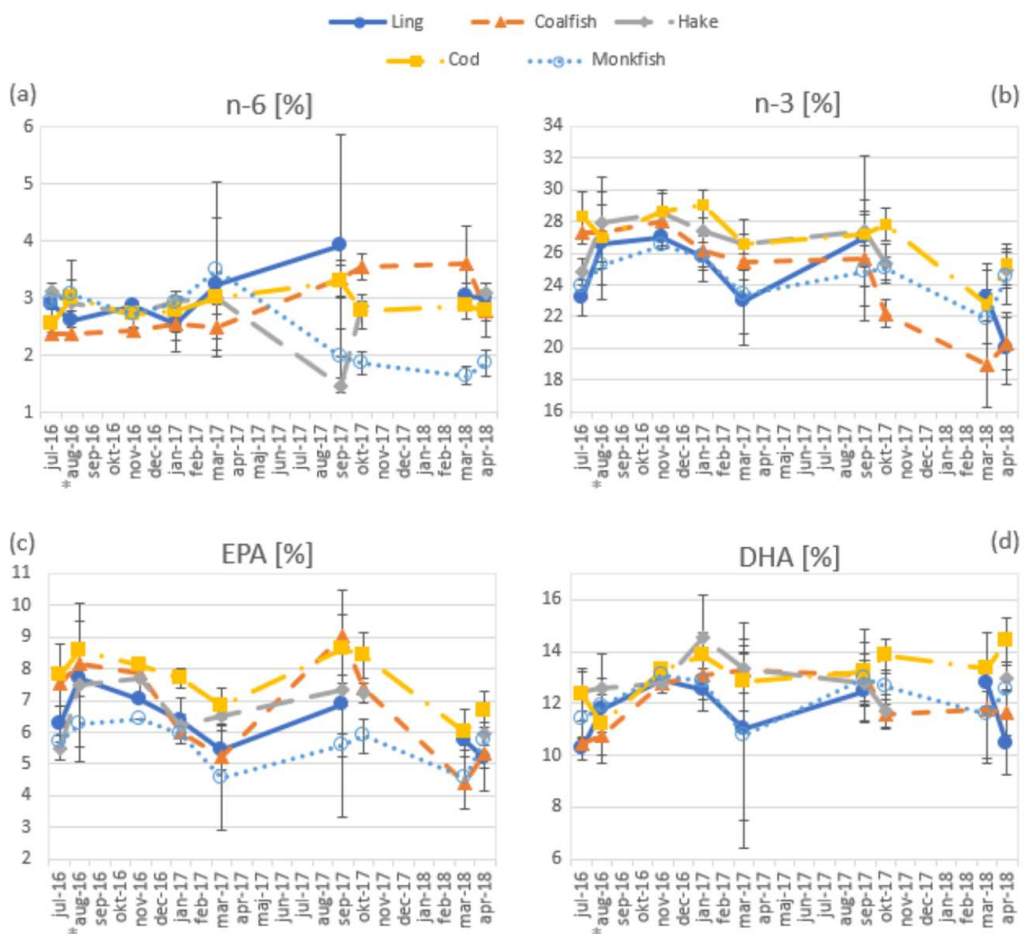

(b)

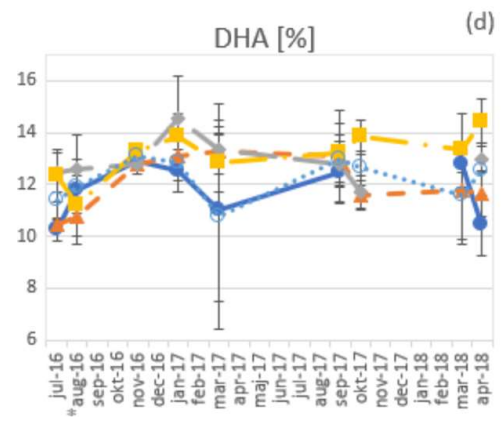


Figure 4. The oil composition, including (a) omega-6\%, (b) omega-3\%, (c) EPA \% and (d) DHA \%, as a function of time of sampling for all fish species. All samples excluding August 2016 are from Karbak while data for August 2016 are based fish caught by Tobis.

\section{Conclusions}

All fish species had similar tendencies of generally lower oil content in the livers in spring and higher content in the fall. This could be due to spawning season or species variations. Cod and hake and to some extent ling had EPA and DHA levels, PV and FFA content which are within the recommended levels for fish oil for human consumption. Livers from monkfish may be less suitable for production of fish oil for human consumption due to their lower content of oil, lower levels of EPA and higher FFA content. Coalfish could potentially be used for fish liver oil production. However, the fluctuating EPA content and PV in coalfish livers may make it difficult to achieve a standardised production of oil. Storage conditions (storage on ice or frozen at sea followed by frozen storage on land until analysis) did not have a significant effect on the content and quality of liver lipids.

Author Contributions: Conceptualization and methodology, Charlotte Jacobsen and Ann-Dorit Moltke Sørensen; writing - original draft preparation, Simone Andrea Warncke, Sussie Hjorth Hansen, writing - review and editing, Charlotte Jacobsen and Ann-Dorit Moltke Sørensen; data analysis and visualization, Ann-Dorit Moltke Sørensen, Simone Andrea Warncke, Sussie Hjorth Hansen; funding acquisition, Charlotte Jacobsen. All authors have read and agreed to the published version of the manuscript.

Funding: This research was funded by Den Europæiske Union. Den Europæiske Hav- og Fiskerifond, grant number 33112-I-15-004

Data Availability Statement: Not applicable

Acknowledgments: Lone Honoré and Anders Barlach are acknowledged for contributions to funding acquisition and coordination of sampling of livers with Karbak and Tobis fishing vessels. The latter are acknowledged for sampling of the livers. Thi Thu Trang Vu is acknowledged for skilled laboratory work.

Conflicts of Interest: The authors declare no conflict of interest. The funders had no role in the design of the study; in the collection, analyses, or interpretation of data; in the writing of the manuscript, or in the decision to publish the results. 

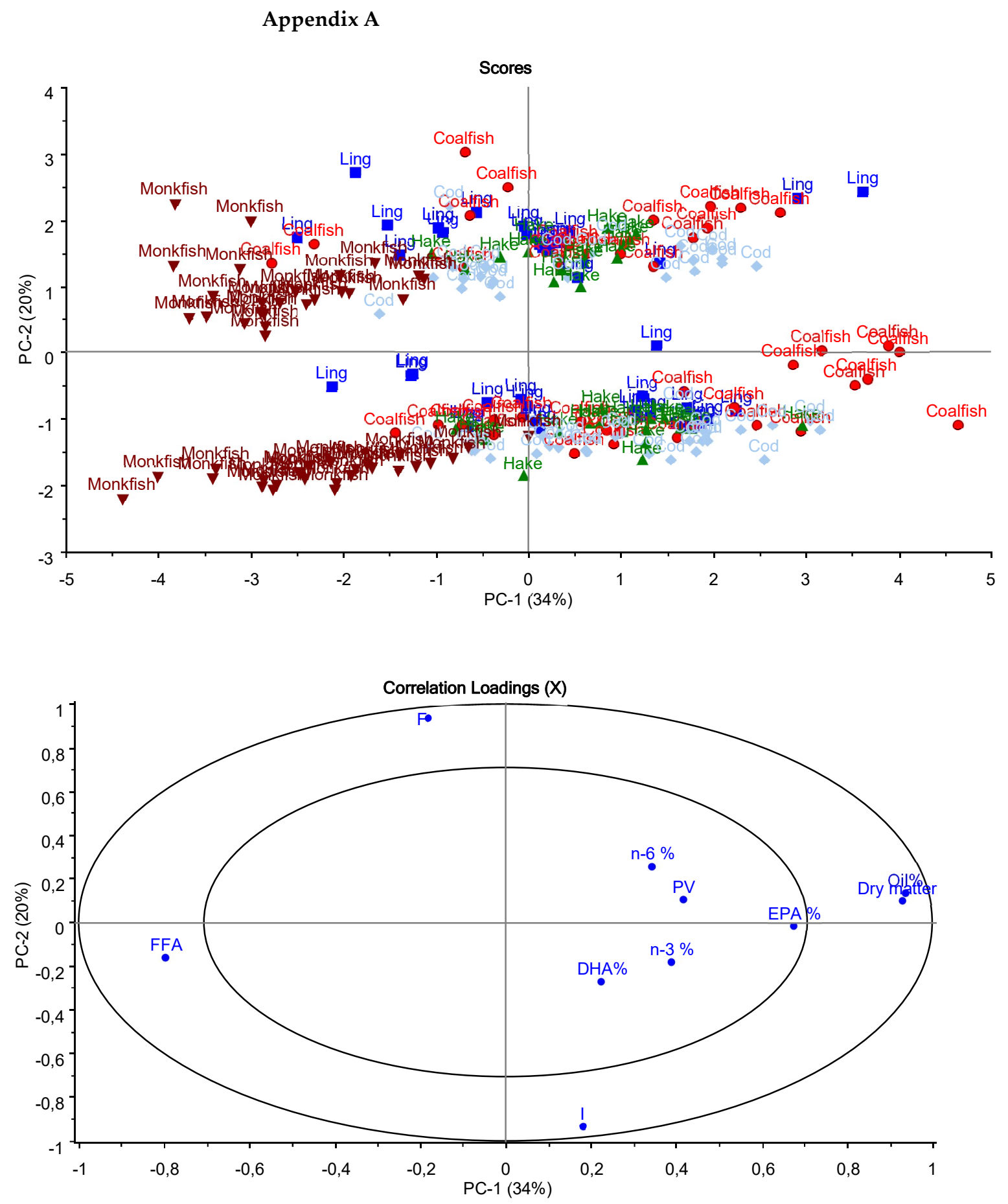

Figure A1. Results from PCA of all samples and their oil content, dry matter, total n-3 PUFA \%, total n-6 PUFA \%, EPA \%, DHA \%, PV, FFA and inforrmation on storage conditions. a) Scores plot, b) Loadings plot. In loadings plot: I Ice storage, $F$ Frozen storage 


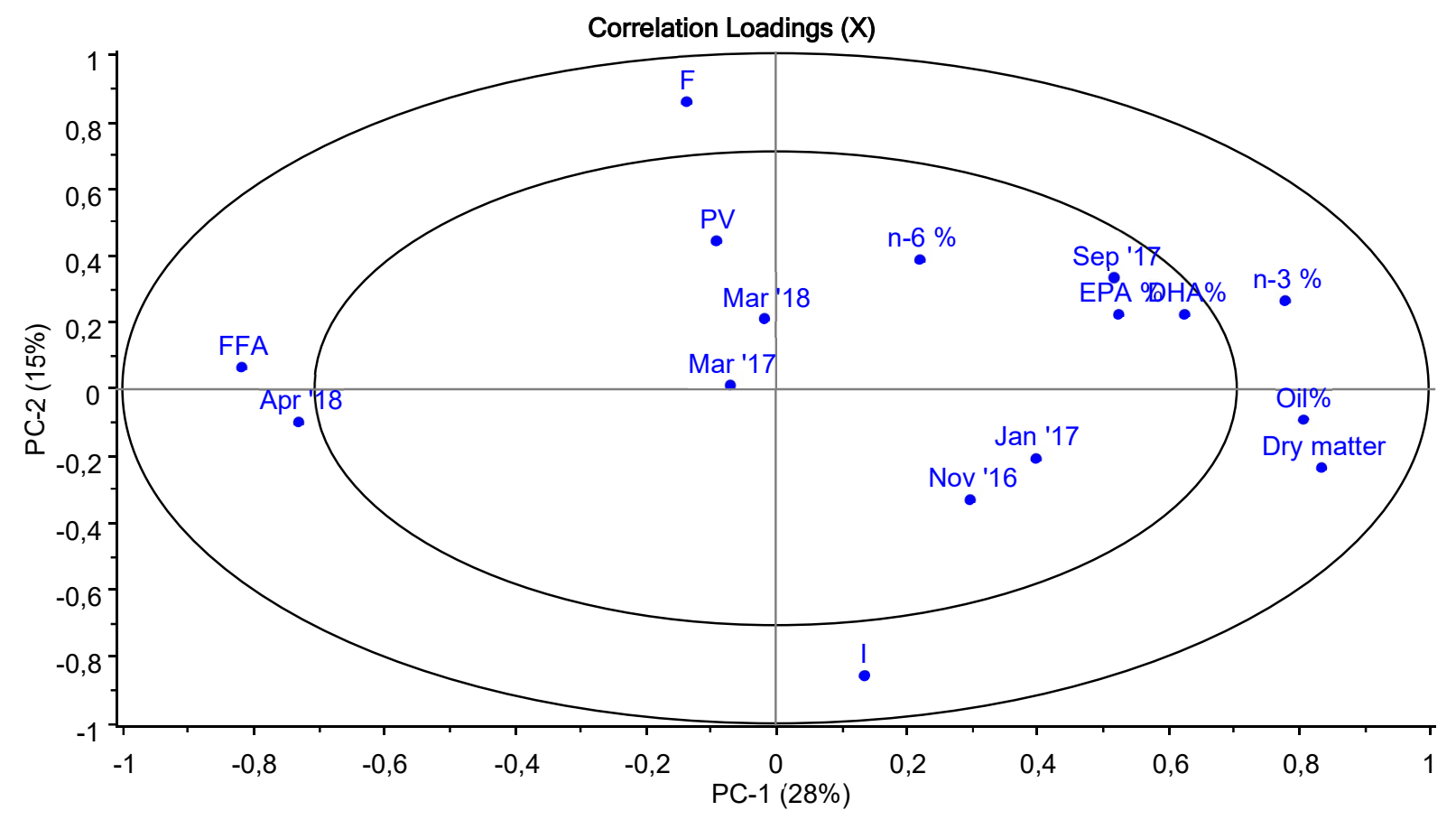

Figure A2. Loadings plot from PCA of ling samples and their oil content, dry matter, total n-3 PUFA \%, total n-6 PUFA \%, EPA \%, DHA \%, PV, FFA and information on storage conditions and sampling time. I Ice storage, F Frozen storage. 


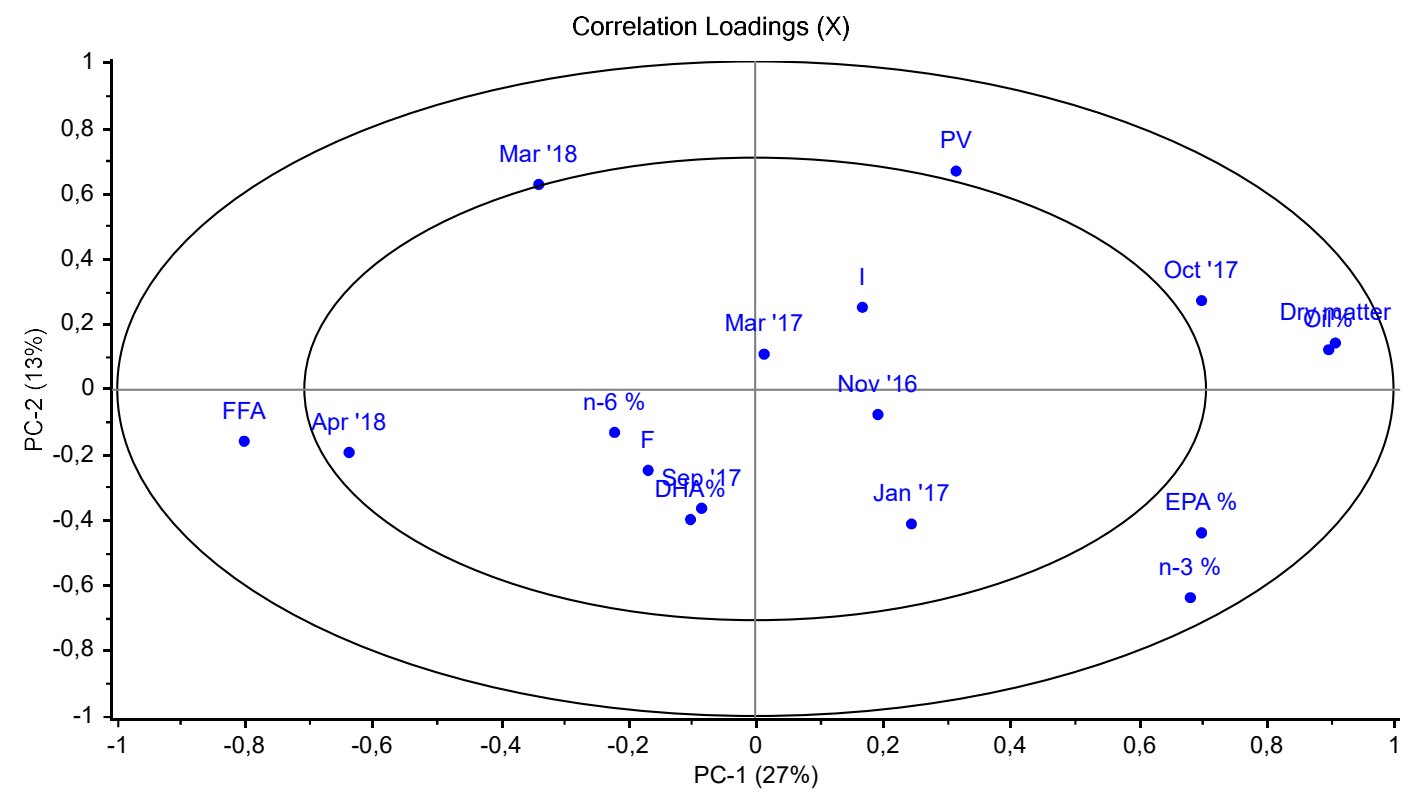

Figure A3. Loadings plot from PCA of cod samples and their oil content, dry matter, total n-3 PUFA \%, total n-6 PUFA \%, EPA \%, DHA \%, PV, FFA and information on storage conditions and sampling time. I Ice storage, $F$ Frozen storage

\section{References}

1. Calder, P.C. Health benefits of omega-3 fatty acids. In Omega-3 Delivery Systems: Production, Physical Characterization and Oxidative Stability, Garcia-Moreno, P.J., Jacobsen, C., Sørensen, A.-D.M, Yesiltas, B. Eds; Elsevier Inc.: Amsterdam, The Netherlands, 2021, pp. 25-53

2. Shahidi, F.; Ambigaipalan, P. Omega-3 Polyunsaturated Fatty Acids and Their Health Benefits. Ann. Rev. Food Sci. Technol. 2018 9, 345-381

3. EFSA Panel on Dietetic Products, Nutrition and Allergies (NDA), EFSA Journal 2011, 9, 2078

4. Nichols, P. D. Fish Oil Sources. In Long-chain Omega-3 Specialty Oils, Breivik, H. Ed.; Woodhead Publishing Ltd: Cambridge, England, 2007, pp. 23-42.

5. Bimbo, A. P. Sources of Omega-3 Fatty Acids. In Food enrichment with omega-3 fatty acids, Jacobsen, C., Horn, A.F:, Sørensen, A.-D.M., Nielsen, N.S. Eds; Woodhead Publishing Ltd: Cambridge England, 2013, pp. 27-107.

6. Isin, A.; Gokoglu. N. Effects of Temperature and Time of Freezing on Lipid Oxidation in Anchovy (Engraulis Encrasicholus) during Frozen Storage. Eur. J. Lipid Sci. Technol. 2014 8, 996-1001.

7. Baron, C.P.; Kjærsgård, I.V.H.; Jessen, F.; Jacobsen, C. Protein and Lipid Oxidation during Frozen Storage of Rainbow Trout (Oncorhynchus Mykiss). J. Agric. Food Chem. 2007, 55, 8118-8125.

8. Rudy, M.D.; Kainz, M.J.; Graeve, M.; Colombo, S.M.; Arts, M.T. Handling and Storage Procedures Have Variable Effects on Fatty Acid Content in Fishes with Different Lipid Quantities. Plos One 2016, 8, e0160497.

9. Statistic Denmark: StatBank Denmark: Landings By Danish Vessels By Region, Harbour, Unit And Type Of Fish https://www.statistikbanken.dk/statbank5a/selectvarval/saveselections.asp. Accessed 28 Dec. 2021.

10. Official methods of analysis AOAC International 16. ed., 1995, Method no. 39.1.02, Moisture in Meat. 
11. Bligh, E. G.; Dyer, W.J. A Rapid Method Of Total Lipid Extraction And Purification. Can. J. Biochem. Physiol. 1959, 37, 911917.

12. AOCS Official Methods and Recommended Practices. 5. udg., AOCS, Champaign, IL, USA, 1998. Official method Ce 1b-89

13. AOCS Official Methods and Recommended Practices. 5. udg., AOCS, Champaign, IL, USA, 1998. Official method Ce 1i-07

14. AOCS Official Methods and Recommended Practices. 5. udg., AOCS, Champaign, IL, USA, 1998. Official Method Ca 5a-40

15. Shantha, N.C.; Decker, E.A. Rapid, Sensitive, Iron-Based Spectrophotometric Methods for Determination of Peroxide Values of Food Lipids. J. AOAC Int. 1994, 77, 421-424.

16. Eliassen, J.-E.; Vahl, O. Seasonal variations in biochemical composition and energy content of liver, gonad and muscle of mature and immature cod, Gadus morhua (L.) from Balsfjorden, northern Norway. J. Fish Biol. 1982, 20 , 707-716.

17. Røjbek, M.C:, Jacobsen, C.; Tomkiewicz, J; Støttrup, J.G. Linking lipid dynamics with the reproductive cycle. in Baltic cod Gadus morhua. Mar. Ecol. Prog. Ser. 2012, 471, 215-234.

18. Falch, E.; Rustad, T.; Jonsdottir, R; Shaw, N.B.; Dumay, J.; Berge, J.P.; Arason, S.; Kerry., J.P.; Sandbakk, M.; Aursand, M. Geographical and seasonal differences in lipid composition and relative weight of by-products from gadiform species. $J$. Food Comp. Anal. 2006, 19, 727-736.

19. Domínguez-Petit, R; Saborido-Rey, F; Medina, I.. Changes of proximate composition, energy storage and condition of European hake (Merluccius merluccius, L. 1758) through the spawning season. Fisheries Research 2010, 104, 73-82.

20. USDA (2018) United States Department of Agriculture - Food Composition Databases http://ndb.nal.usda.gov/- Accessed 17 Dec. 2018

21. Méndez, E. Seasonal changes in the lipid classes and fatty acid compositions of hake (Merluccius hubbsi) liver oil. JAOCS $199774,1173-1175$.

22. McGill, A.S.; Moffat, C.F. A Study of the Composition of Fish Liver and Body Oil Triglycerides. LIPIDS 1992, 27, 360-370.

23. Madsen, S. Fisk, Krebs og Bløddyr, Fra hav til bord - om fiskens rette behandling, Fiskericirklen: Danmark, 2005, pp.115158.

24. Ottera, H.; Carlehög, M.; Karlsen, Ø. Effect of Diet and Season on Quality of Farmed Atlantic Cod (Gadus Morhua L.). Lwt-food Sci. Technol. 2007 40, 1623-1629.

25. Herland, H.; Esaiassen, M.; Cooper, M.; Olsen, R.L.Quality of Farmed Atlantic Cod: Effects of Season and Storage. Aquacult. Res. 2010 41, 1203-1210.

26. Sandeman, L. R.; Yaragina, N.A.; Marshall, C.T. Factors Contributing to Inter- and Intra-Annual Variation in Condition of Cod Gadus Morhua in the Barents Sea. J. Animal Ecol. 2008 77, 725-734.

27. Malcolm, J.; Leknes.O. Cod Liver Oil: Feed Oil Influences on Fatty Acid Composition. Aquacult. Internat. 2010, 18, $223-230$.

28. frida.fooddata.dk 2018, https://frida.fooddata.dk/index.php?lang=en Accessed 17 December 2018

29. Bimbo, A.P. Production of Marine Oils. In Omega-3 Oils: Applications in Functional Foods, Hernandez, E.M., Hosokawa, M, H. Eds; AOCS Press: Champaign, IL, 2011, pp 73-105. 